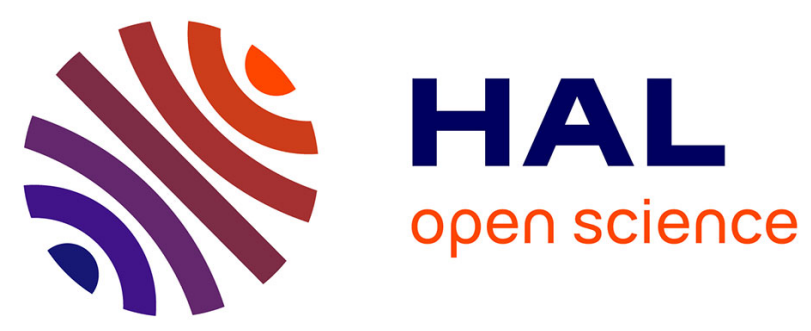

\title{
A Seed-Mediated Approach for the Preparation of Modified Heterogeneous Catalysts
}

Justine Harmel, Adrien Berliet, Kassiogé Dembélé, Cécile Marcelot, Anne-Sophie Gay, Ovidiu Ersen, Sylvie Maury, Antoine Fecant, Bruno Chaudret, Philippe Serp, et al.

\section{To cite this version:}

Justine Harmel, Adrien Berliet, Kassiogé Dembélé, Cécile Marcelot, Anne-Sophie Gay, et al.. A SeedMediated Approach for the Preparation of Modified Heterogeneous Catalysts. ChemCatChem, 2018, 10 (7), pp.1614-1619. 10.1002/cctc.201701860 . hal-01884915

\section{HAL Id: hal-01884915 https://hal-ifp.archives-ouvertes.fr/hal-01884915}

Submitted on 19 Oct 2018

HAL is a multi-disciplinary open access archive for the deposit and dissemination of scientific research documents, whether they are published or not. The documents may come from teaching and research institutions in France or abroad, or from public or private research centers.
L'archive ouverte pluridisciplinaire HAL, est destinée au dépôt et à la diffusion de documents scientifiques de niveau recherche, publiés ou non, émanant des établissements d'enseignement et de recherche français ou étrangers, des laboratoires publics ou privés. 
Heterogeneous \& Homogeneous \& Bio- \& NanoCHEMCATCHEM CATALYSIS

\section{Accepted Article}

Title: A seed-mediated approach for the preparation of modified heterogeneous catalysts

Authors: Katerina Soulantica, Justine Harmel, Adrien Berliet, Kassiogé Dembélé, Cécile Marcelot, Anne-Sophie Gay, Ovidiu Ersen, Sylvie Maury, Antoine Fécant, Bruno Chaudret, and Philippe Serp

This manuscript has been accepted after peer review and appears as an Accepted Article online prior to editing, proofing, and formal publication of the final Version of Record (VoR). This work is currently citable by using the Digital Object Identifier (DOI) given below. The VoR will be published online in Early View as soon as possible and may be different to this Accepted Article as a result of editing. Readers should obtain the VoR from the journal website shown below when it is published to ensure accuracy of information. The authors are responsible for the content of this Accepted Article.

To be cited as: ChemCatChem 10.1002/cctc.201701860

Link to VoR: http://dx.doi.org/10.1002/cctc.201701860 
WILEY-VCH

\title{
A seed-mediated approach for the preparation of modified heterogeneous catalysts
}

\author{
Justine Harmel, ${ }^{[a, b]}$ Adrien Berliet, ${ }^{[c]}$ Kassiogé Dembélé, ${ }^{[d]}$ Cécile Marcelot, ${ }^{[a e]}$ Anne-Sophie Gay, ${ }^{[c]}$ \\ Ovidiu Ersen, ${ }^{[d]}$ Sylvie Maury, ${ }^{[c]}$ Antoine Fécant, ${ }^{[c]}$ Bruno Chaudret, ${ }^{[a]}$ Philippe Serp, ${ }^{[b]},{ }^{*}$ Katerina \\ Soulantica ${ }^{[\mathrm{a}],{ }^{*}}$
}

\begin{abstract}
Colloidal chemistry is very efficient in providing nanocrystals of well controlled structural characteristics. While nanoparticles are essential components of heterogeneous catalysts, colloidal methods rarely employed for their preparation. We have employed a seed mediated growth approach for modifying the structural characteristics of a conventional cobalt-based FischerTropsch catalyst. The Co particles of this catalyst can play the role of seeds for the overgrowth of shape and structure controlled cobalt nanostructures using a simple wet chemical method involving a molecular cobalt precursor and stabilizing agents. Thus, cobalt nanorods exhibiting the hexagonal compact structure were selectively grown on the immobilized Co particles of a reference $\mathrm{Co} / \mathrm{Al}_{2} \mathrm{O}_{3}-\mathrm{SiO}_{2}$ catalyst. The as obtained catalyst shows a better stability than a reference catalyst for the Fischer-Tropsch reaction. The removal of most of the ligands from the nanorod catalyst allows improving the catalyst activity while maintaining its stability. This is a proof of concept concerning the implementation of wet chemistry nanoparticle synthesis for the modification of heterogeneous catalysts.
\end{abstract}

\section{Introduction}

Heterogeneous catalysts employed in industrial reactions are multicomponent systems in which the catalytically active phase is in the majority of the cases inhomogeneous in terms of crystallite size, shape and sometimes crystal structure. Catalytic activity, selectivity and stability being affected by catalyst microstructure, the possibility to tune the size, the shape and the crystal structure of the catalytically active phase offers the opportunity to optimize its performances. ${ }^{[1]}$ Wet chemical routes have recently progressed enough to allow a fine control of nano-object

[a] LPCNO, Université de Toulouse, CNRS, INSA, UPS, 135 avenue de Rangueil, 31077 Toulouse, France. E-mail : ksoulant@insatoulouse.fr

[b] LCC, CNRS-UPR 8241, ENSIACET, Université de Toulouse, Toulouse, France. E-mail : pserp@ensiacet.fr

[c] IFP Energies Nouvelles, Rond-point de l'échangeur de Solaize, 69360 Solaize, France.

[d] Institut de Physique et Chimie des Matériaux de Strasbourg (IPCMS), 23 rue du Loess, 67034 Strasbourg

[e] CEMES-CNRS, 29 rue Jeanne Marvig, B.P. 94347, 31055 Toulouse, France. characteristics, including their chemical composition, which can be now finely tuned. ${ }^{[2]}$ In this context, fine tuning of catalyst nanoparticles through wet chemical route syntheses could improve heterogeneous catalytic system performances through the introduction of specific characteristics to the catalyst, enabling the establishment of structure-performance relations in model catalysts and their subsequent translation into realistic systems. ${ }^{[3]}$

The Fischer Tropsch Synthesis (FTS) is a catalytic process that converts synthesis gas (syngas, $\mathrm{CO} / \mathrm{H}_{2}$ ), which can be obtained from various sources such as coal, natural gas, naphtha or biomass, into hydrocarbons and water. ${ }^{[4]}$ This process attracts a lot of research attention as the products obtained consist in clean and high quality jet fuel and diesel. Currently, there are two FTS operating modes: high- and low-temperature FTS processes. ${ }^{[5]}$ Both $\mathrm{Fe}$ and $\mathrm{Co}$ catalysts can be used in the lowtemperature FTS $\left(200-240^{\circ} \mathrm{C}\right)$ process to produce linear longchain hydrocarbon waxes and paraffins in fixed bed or slurry reactors. ${ }^{[6]}$ Cobalt catalysts are more active, present a longer lifetime, and have a simpler product slate of mainly paraffins and some $\alpha$-olefins. The FTS is a reaction for which structure sensitivity has been demonstrated. Numerous studies have been devoted to rationalizing the influence of the microstructure of cobalt-based catalysts on their catalytic performances (activity/selectivity). ${ }^{[4 c]}$ Apart from the particle size that has been shown to play an important role, $\left.{ }^{[5,}, 7\right]$ the crystal structure might also influence the catalytic performances. This is especially relevant for catalyst systems based on cobalt, since cobalt crystallizes mainly in two structures: face centered cubic (fcc) and hexagonal close packed $(h c p)$. Several works suggest that the Co-hcp structured catalysts present a higher activity. ${ }^{[8]}$ Furthermore, activity is shape dependent since theoretical studies indicate that it is influenced by the crystal facet type exposed. ${ }^{[9]}$

Some of us have reported the controlled synthesis in solution of purely metallic cobalt nanorods (NRs) crystallized in the hcp structure and exposing (11-20) facets. ${ }^{[10]}$ They can be prepared by reduction under $\mathrm{H}_{2}$ of $\left[\mathrm{Co}\left\{\mathrm{N}\left(\mathrm{SiMe}_{3}\right)_{2}\right\}_{2}\right.$ (thf)] in the presence of lauric acid (LA) and hexadecylamine (HDA). Since $\mathrm{Co}(0)$ is the active catalyst phase, these NRs can be employed as FTS catalysts without any post-synthesis reduction step. In addition, thanks to their well-controlled shape, the exposure of a large majority of (11-20) facets could give information on the catalytic performances of these specific facets.

In addition to catalytic activity and product selectivity, catalyst deactivation is a crucial issue for industrial FTS catalyst development. The activity of Co-based FTS catalysts is deteriorated during their operation; the main suspected reasons, 
with varying contributions according to operating conditions, are: i) oxidation of the surface Co atoms, ii) Co-support interactions and formation of mixed compounds that are reducible only at high temperatures, iii) sintering, iv) refractory coke formation, v) loss of cobalt because of attrition, and (vi) hetero atom poisoning (e.g. sulfur). ${ }^{[8 \mathrm{~d}, 11]}$.Therefore, improving catalyst stability is a major concern among technology providers and plant operators. Different strategies, most of them related to catalyst operation, have been followed to improve Co-based catalyst stability. ${ }^{[4 \mathrm{~b}, 12]}$ However, considering the very long reaction time necessary to accurately evaluate catalyst stability under FTS conditions (typically 400-500 hrs), relatively few studies have been published so far on this critical aspect. ${ }^{[8 d, 11 c, d]}$

We report herein the modification of a conventional nonpromoted $\mathrm{Co} / \mathrm{Al}_{2} \mathrm{O}_{3}-\mathrm{SiO}_{2}$ FTS catalyst by growing anisotopic hcpcobalt nanostructures on the Co particles of the pristine catalyst, ${ }^{[13]}$ and the remarkable stability of the resulting modified catalyst under FTS conditions in a slurry reactor. Wet chemistry methods have been employed for Co overgrowth from a solution containing a molecular $\mathrm{Co}$ (II) precursor. To the best of our knowledge this innovative approach has never been employed on heterogeneous catalysts.

\section{Results and Discussion}

The possibility to synthesize purely metallic Co NRs of homogeneous dimensions [10, 14] incited us to use them as catalysts after immobilization on a conventional oxide support $\mathrm{Al}_{2} \mathrm{O}_{3}-\mathrm{SiO}_{2}$. However, the impregnation with pre-synthesized cobalt NRs did not produce a homogeneous distribution of the Co NRs inside the support. Figure S1 in the Supporting Information (SI) presents transmission electron microscopy (TEM) and scanning transmission electron microscopy-energy-dispersive $\mathrm{X}$ ray spectroscopy (STEM-EDX) results that show the accumulation of the Co NRs on the support surface. This is not surprising considering the NR shape and dimensions (length: 53 $\pm 5 \mathrm{~nm}$, diameter: $4.9 \pm 0.9 \mathrm{~nm}$ ), and the textural properties of the support (mean pore diameter $=9.2 \mathrm{~nm}$ ). Alternatively, the NR synthesis was performed in the presence of the support. In contrast to the cobalt NRs, the cobalt precursor solution should easily diffuse in the support porosity, allowing the formation of NRs in the pores during the reduction step. However, heating a toluene solution containing [Co $\left\{\mathrm{N}\left(\mathrm{SiMe}_{3}\right)_{2}\right\}_{2}$ (thf)], LA and HDA $(\mathrm{Co} / \mathrm{HDA} / \mathrm{LA}=1 / 1.7 / 1.2)$ at $110^{\circ} \mathrm{C}$ under $\mathrm{H}_{2}$ resulted in an extended nucleation of Co NRs and nanoparticles, mainly in the solution. (Figure S2 in SI). In addition, all attempts to separate the NRs formed in solution by washing the product resulted in the liberation of the Co nano-objects from the support, pointing towards an insufficient interaction of the Co with the $\mathrm{Al}_{2} \mathrm{O}_{3}-\mathrm{SiO}_{2}$ support. Thus, both impregnation and in situ formation of Co NRs on the $\mathrm{Al}_{2} \mathrm{O}_{3}-\mathrm{SiO}_{2}$ support were unsuccessful.

The so called seeded growth (or seed-mediated growth) is a powerful strategy for the synthesis of a variety of nanocrystals. ${ }^{[15]}$ Inspired by this approach, we took advantage of Co particles already immobilized on a support, i.e. Co particles of a conventional FTS catalyst prepared by a standard impregnation method, and used them as seeds on which hcp-cobalt NRs could overgrow from a solution containing molecular cobalt. Indeed, some of us have recently shown that purely hcp Co NRs and nanowires (NWs) can be grown from a solution containing $\left[\mathrm{Co}\left\{\mathrm{N}\left(\mathrm{SiMe}_{3}\right)_{2}\right\}_{2}\right.$ (thf)], LA and HDA, on crystallographically oriented metallic substrates, which play the role of seeds for the epitaxial Co growth. ${ }^{[16]}$ These studies have demonstrated that the solution composition dictates the crystallographic structure and the shape of the Co nanostructures, and this independently of the substrate nature and crystallographic orientation. Indeed, hcp Co $\mathrm{NRs}$ /NWs have been obtained in all cases, their growth starting either from (111) fcc or (0001) hcp surfaces of various metallic films, and even on the surface of bulk metals. Thus, by controlling the solution composition, the Co overgrowth could take place anisotropically on the surface of (111) fcc or (0001) hcp 6-fold symmetry facets of the Co particles of the catalyst, which would play the role of seeds. ${ }^{[16 \mathrm{~b}]}$ To validate this approach, we first used a conventional $15 \% \mathrm{Co} / \mathrm{Al}_{2} \mathrm{O}_{3}-\mathrm{SiO}_{2}$ catalyst $\left(\mathrm{S}_{\mathrm{BET}}=128 \mathrm{~m}^{2} / \mathrm{g}\right.$, pore volume $=0.32 \mathrm{~mL} / \mathrm{g}$, mean pore diameter $=10 \mathrm{~nm}$ ) prepared as described in the experimental section, for which the particles presented a broad size distribution (Figure S3 in SI). In this catalyst, cobalt is crystallized mainly in the fcc structure, and the $\mathrm{Co}(0)$ amount after reduction is around $88 \%$ as estimated by temperature programmed reduction (TPR) analysis. This catalyst was introduced in a toluene solution containing $\left[\mathrm{Co}\left\{\mathrm{N}\left(\mathrm{SiMe}_{3}\right)_{2}\right\}_{2}\right.$ (thf)], HDA and LA with different Co/HDA/LA ratios. The $\left[\mathrm{Co}\left\{\mathrm{N}\left(\mathrm{SiMe}_{3}\right)_{2}\right\}_{2}\right.$ (thf)] amount was first fixed so that a total Co loading of $25 \%$ was obtained after complete reduction of the Co precursor in solution. Figure 1 presents the modified catalysts obtained by heating four mixtures of [Co\{ $\left.\mathrm{N}\left(\mathrm{SiMe}_{3}\right)_{2}\right\}_{2}$ (thf)], HDA, LA and $15 \% \mathrm{Co} / \mathrm{Al}_{2} \mathrm{O}_{3}-\mathrm{SiO}_{2}$ in toluene at $110^{\circ} \mathrm{C}$ under 3 bars of $\mathrm{H}_{2}$ for 24 hours. In these mixtures the $\mathrm{Co} / \mathrm{HDA} / \mathrm{LA}$ ratio has been varied, keeping the Co concentration constant. Although Co NRs can normally grow from a solution containing Co, HDA and $L A$ in a molar ratio of $1 / 1.7 / 1.2$ $(\mathrm{Co} / \mathrm{HDA} / \mathrm{LA})^{[10 \mathrm{bb}]}$ in the absence of any support, it can be seen from Figures $1 \mathrm{a}-\mathrm{d}$ that in the presence of the $15 \% \mathrm{Co} / \mathrm{Al}_{2} \mathrm{O}_{3}-\mathrm{SiO}_{2}$ catalyst it was necessary to increase the amount of ligands, and particularly that of LA, in order to obtain quantitatively anisotropic nano-objects (NRs/NWs). This is attributed to the adsorption of part of the ligands on the $15 \% \mathrm{Co} / \mathrm{Al}_{2} \mathrm{O}_{3}-\mathrm{SiO}_{2}$ catalyst, which modifies the Co/HDA/LA ratio in the solution and affects the shape of the growing nano-objects. Indeed, in a previous work and in the absence of any support we have shown that the Co/HDA/LA ratio is very important for the reaction outcome as far as shape and crystal structure are concerned. ${ }^{[17]}$, a high LA/Co ratio favoring the formation of anisotropically shaped hcp nanostructures. Thus, cobalt $\mathrm{NRs} / \mathrm{NWs}$ on the pristine $\mathrm{Co} / \mathrm{Al}_{2} \mathrm{O}_{3}-\mathrm{SiO}_{2}$ catalyst were selectively obtained for Co/HDA/LA molar ratio of $1 / 2 / 2.5$ and $1 / 2 / 3$. For the rest of this study, the ratio was fixed to $1 / 2 / 3$, since it gives rise to an exclusive growth on the $15 \% \quad \mathrm{Co} / \mathrm{Al}_{2} \mathrm{O}_{3}-\mathrm{SiO}_{2}$ catalyst, without any homogeneous nucleation of cobalt in solution. This was confirmed by TEM examination of the colorless supernatant obtained after reaction. Since the preexisting nanoparticles and the overgrowing from the solution metal are the same, we have no possibility to directly evidence that Co $\mathrm{NRs} / \mathrm{NWs}$ overgrow only on the surface of the Co particles 
present on the parent $\mathrm{Co}$ catalyst and not on the $\mathrm{Al}_{2} \mathrm{O}_{3}-\mathrm{SiO}_{2}$ support. Therefore, we performed a blank experiment in which a solution of $\mathrm{Co} / \mathrm{HDA} / \mathrm{LA}$ of a 1/2/2 ratio was heated under $\mathrm{H}_{2}$ in the presence of bare $\mathrm{Al}_{2} \mathrm{O}_{3}-\mathrm{SiO}_{2}$, Co multipods grow only in solution while the color of the support remains white. We can therefore conclude that the NRs/NWs grow only on the surface of the Co particles of the pristine catalyst.
As described in the Experimental section, the Co seeds of the pristine catalyst were reduced prior to the Co NRs/NWs growth. We have seen that although it is possible to grow Co NRs on $\mathrm{CoO}$, this is not possible on $\mathrm{Co}_{3} \mathrm{O}_{4}$ (Figure $\mathrm{S} 4, \mathrm{SI}$ ). The difference in lattice parameters between $h c p-C o(a=4.057 \AA)$, $\mathrm{CoO}(\mathrm{a}=4.260 \AA)$ and $\mathrm{Co}_{3} \mathrm{O}_{4}(8.084 \AA)$ is presumably at the origin of this result.

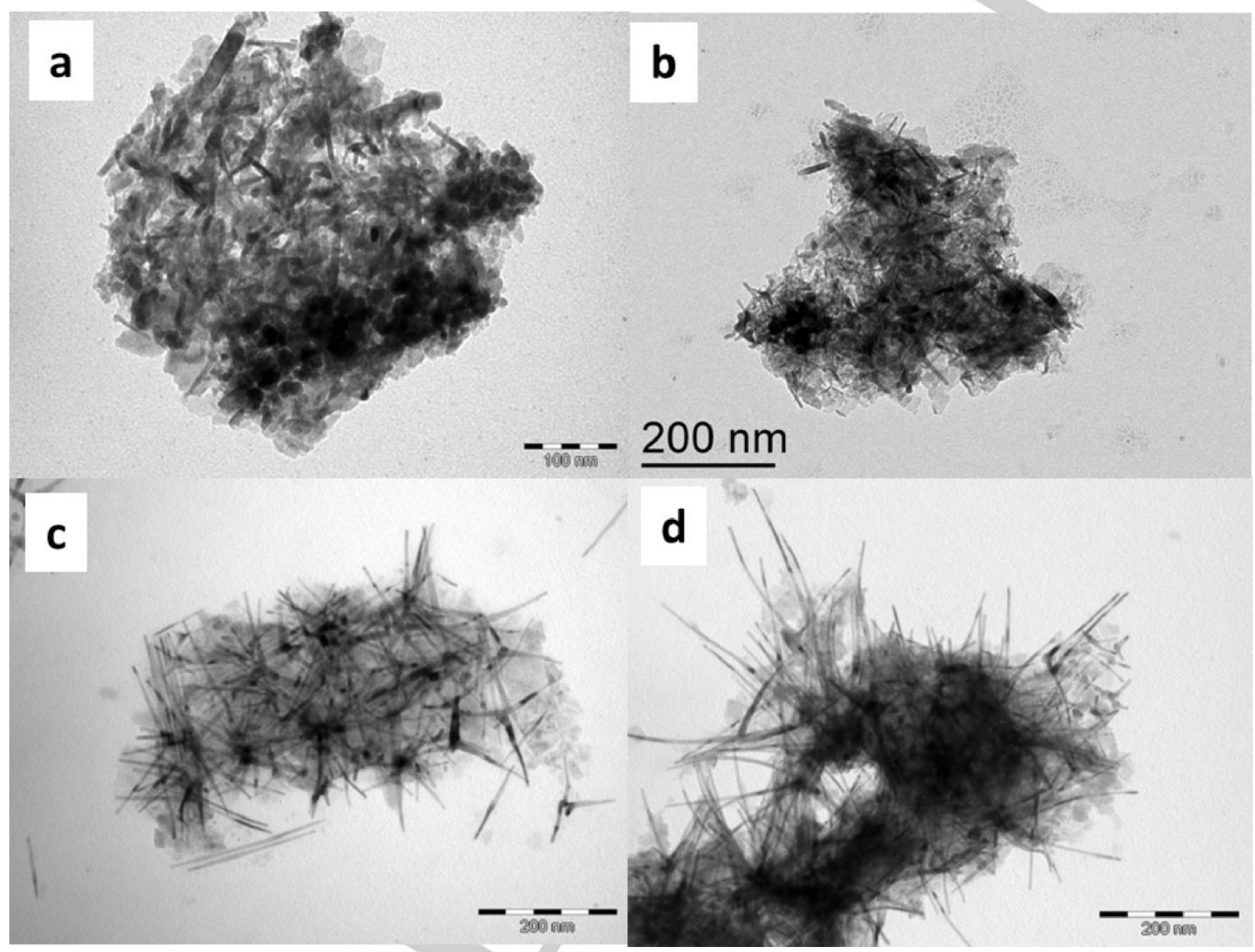

Figure 1. Co nano-objects obtained by decomposition of $\left[\mathrm{Co}\left\{\mathrm{N}\left(\mathrm{SiMe}_{3}\right)_{2}\right\}_{2}(\mathrm{thf})\right]$ on a $15 \% \mathrm{Co} / \mathrm{Al}_{2} \mathrm{O}_{3}-\mathrm{SiO}_{2}$ catalyst at different $\mathrm{Co} / \mathrm{HDA} / \mathrm{LA}$ ratios: a) $\mathrm{Co} / \mathrm{HDA} / \mathrm{LA}=$ 1/1.7/1.2; b) Co/HDA/LA = 1/2/2; c) Co/HDA/LA = 1/2/2.5; and d) Co/HDA/LA =1/2/3. Scale bars: a) $100 \mathrm{~nm}, \mathrm{~b}-\mathrm{d}) 200 \mathrm{~nm}$.

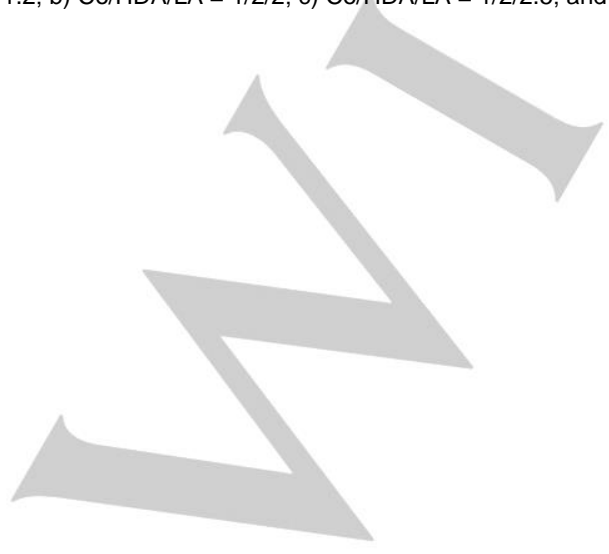


Once the optimal $1 / 2 / 3$ ratio fixed, and in order to compare to a well-studied reference catalyst, the initial cobalt loading was reduced so that the total loading after overgrowth corresponds to a realistic value for $\mathrm{FTS}$. Thus, a conventional $8 \% \mathrm{Co} / \mathrm{Al}_{2} \mathrm{O}_{3}-\mathrm{SiO}_{2}$ catalyst was employed $\left(\mathrm{S}_{\mathrm{BET}}=157 \mathrm{~m}^{2} / \mathrm{g} ; \mathrm{Vp}=0.43 \mathrm{~mL} / \mathrm{g}\right.$, average pore diameter $=9.8 \mathrm{~nm}, \mathrm{Co}(0)$ crystallite size $12.7 \mathrm{~nm})$, on which $7 \% \mathrm{w} / \mathrm{w}$ additional cobalt was deposited from the $\left[\mathrm{Co}\left\{\mathrm{N}\left(\mathrm{SiMe}_{3}\right)_{2}\right\}_{2}\right.$ (thf)] decomposition in the presence of HDA and LA. Figure $2 \mathrm{a}$ and $2 \mathrm{~b}$ show respectively a TEM and a STEM-high angle annular dark field (STEM-HAADF) micrograph of the as obtained material. The NRs/NWs length measured by TEM is 52.6 $\pm 13.6 \mathrm{~nm}$, the diameter being variable within the whole length. TEM observations of a sample obtained by ultramicrotomy indicate that the Co NRs grow both on the surface and in the porosity of the catalyst (Figure S5 in SI). However, it has to be noted that the shape of the Co nano-objects grown in the interior of the grains is not always anisotropic. SEM observations of the catalyst powder (Figure 2c-d) show that its granulometry is not

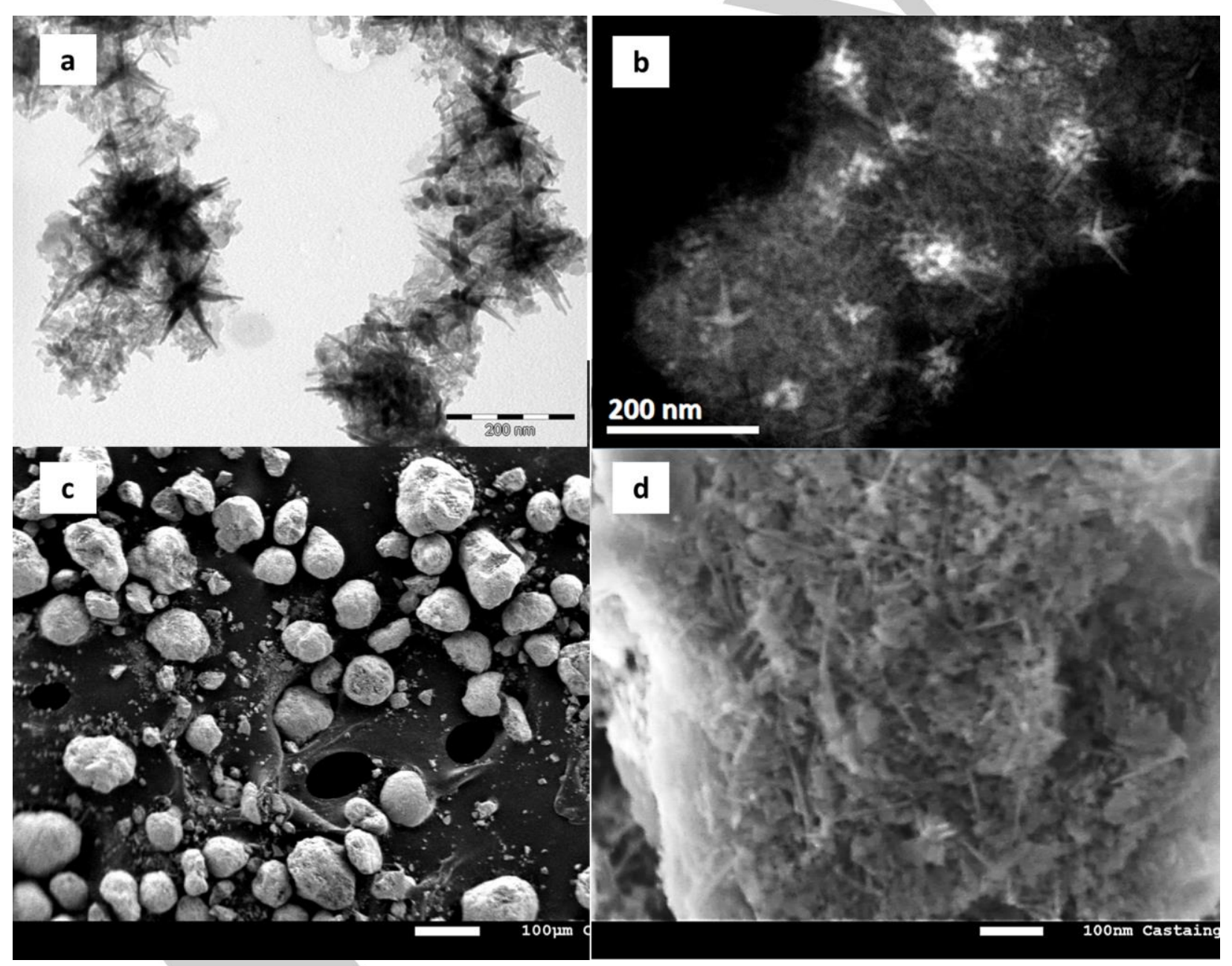

affected by the growth of the Co NRs, and that the NRs/NWs are present on the catalyst grains. SEM-EDX analyses evidence that the cobalt is uniformly distributed on the surface of the catalyst particles (Figure $\mathrm{S} 6$ in $\mathrm{SI}$ ). While quantitative analysis is not possible due to the interference of the support, the XRD diffractogram (Figure 3) of the $7 \% \mathrm{Co} / 8 \% \mathrm{Co} / \mathrm{SiO}_{2}-\mathrm{Al}_{2} \mathrm{O}_{3}$ catalyst shows the increase of the Co hcp phase, compared to the parent catalyst. Indeed, two $h c p$-specific peaks (48.7 and 55.5 characteristic of (100) and (101) diffraction plans of hcp-Co respectively) are more intense in the modified catalyst. These conclusions are corroborated by TEM Selected Area Diffraction (SAED) observations, which show that the whole multipode is composed of a mixture of $f c c-$ and $h c p$-Co, while the podes are composed of hcp Co (Figure S7 in SI).

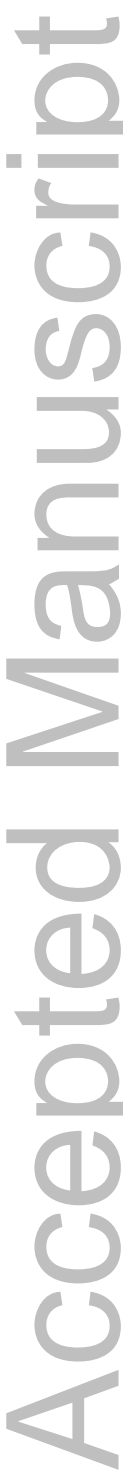

Figure 2. Co nano-objects obtained by decomposition of $\left[\mathrm{Co}\left\{\mathrm{N}\left(\mathrm{SiMe}_{3}\right)_{2}\right\}_{2}(\mathrm{thf})\right]$ on a $8 \% \mathrm{Co}_{\mathrm{Al}} \mathrm{Al}_{2} \mathrm{O}_{3}-\mathrm{SiO}_{2}$ catalyst: a) TEM; b) STEM-HAADF image of a typical aggregate illustrating the shape and the localization of the anisotropic Co nano-objects on the support.; c) SEM overview of the modified catalyst and d) SEM micrograph of higher magnification (scale bars: a), b) $=200 \mathrm{~nm}, \mathrm{c})=100 \mu \mathrm{m} ; \mathrm{d})=100 \mathrm{~nm}$ ). 
Other signals centered around $52^{\circ}$ and $61^{\circ}$ are detected, corresponding to the presence of $f c c$-Co particles, presumably due to the seed $\mathrm{Co}$ particles of the $8 \% \mathrm{Co} / \mathrm{SiO}_{2}-\mathrm{Al}_{2} \mathrm{O}_{3}$. ICP analysis indicates $13 \% \mathrm{Co} \mathrm{w} / \mathrm{w}$ in the final catalyst, and TGA analyses reveal that $8.4 \% \mathrm{w} / \mathrm{w}$ of organic ligands are present.

The performances of the $7 \% \mathrm{Co} / 8 \% \mathrm{Co} / \mathrm{SiO}_{2}-\mathrm{Al}_{2} \mathrm{O}_{3}$ catalyst were monitored in the low-temperature FTS slurry process for 475 hours. For comparison, a $15 \% \mathrm{Co} / \mathrm{SiO}_{2}-\mathrm{Al}_{2} \mathrm{O}_{3}$ conventional catalyst was used as a reference. In Figure 4 we present the catalytic activities of these catalysts. An excellent stability can be noticed for the $7 \% \mathrm{Co} / 8 \% \mathrm{Co} / \mathrm{SiO}_{2}-\mathrm{Al}_{2} \mathrm{O}_{3}$ catalyst, which is not deactivated after $475 \mathrm{~h}$ TOS. While the reference catalyst is initially more active than the $7 \% \mathrm{Co} / 8 \% \mathrm{Co} / \mathrm{SiO}_{2}-\mathrm{Al}_{2} \mathrm{O}_{3}$ modified catalyst, a deactivation process leads to an equalization tendency for the activities as compared to the $7 \% \mathrm{Co} / 8 \% \mathrm{Co} / \mathrm{SiO}_{2}-\mathrm{Al}_{2} \mathrm{O}_{3}$ catalyst. The TEM micrographs and XRD diagram of the $7 \% \mathrm{Co} / 8 \% \mathrm{Co} / \mathrm{SiO}_{2}-\mathrm{Al}_{2} \mathrm{O}_{3}$ catalyst after reaction are presented in Figure S8 in SI. While the anisotropic shape seems not to be retained, TEM observation of samples obtained by ultramicrotomy have shown that $\mathrm{Co}$ is present as nanoparticles of about $20 \mathrm{~nm}$, accumulated in aggregates of 100-200 nm. Furthermore, XRD diffractograms of the catalyst before and after the catalytic run evidence that the small amount of $\mathrm{CoO}$, which was present on the fresh catalyst, is reduced during the catalytic run with a simultaneous increase of the hcp Co component.

The catalyst synthesis through this colloidal method, which allows the Co overgrowth on the $\mathrm{Co}$ of the $8 \% \mathrm{Co} / \mathrm{Al}_{2} \mathrm{O}_{3}-\mathrm{SiO}_{2}$ precursor catalyst and makes use of organic stabilizers (LA and HDA), does not allow their complete elimination by simple washing.

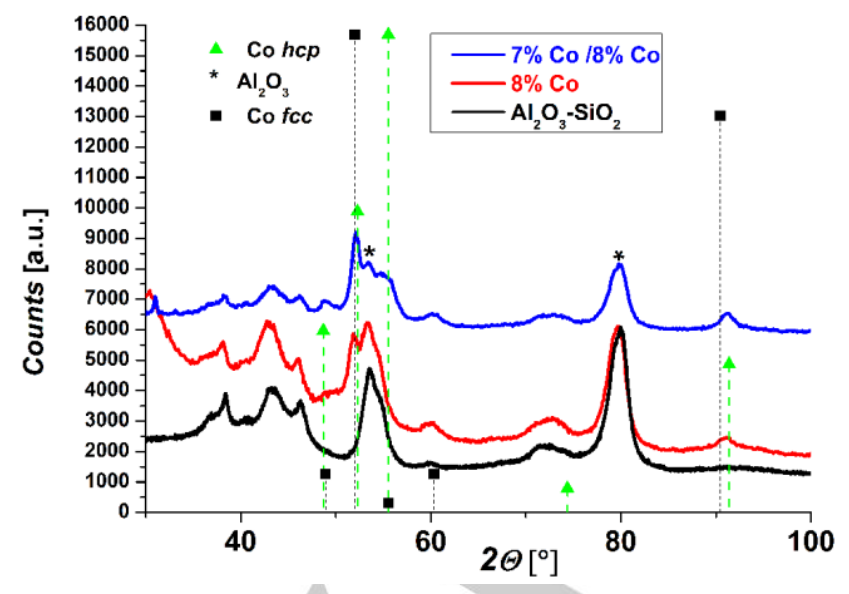

Figure 3. XRD diagrams of the $\mathrm{SiO}_{2}-\mathrm{Al}_{2} \mathrm{O}_{3}$ support (black), the $8 \% \mathrm{Co} / \mathrm{SiO}_{2}$ $\mathrm{Al}_{2} \mathrm{O}_{3}$ parent catalyst (red), and the $7 \% \mathrm{Co} / 8 \% \mathrm{Co} / \mathrm{SiO}_{2}-\mathrm{Al}_{2} \mathrm{O}_{3}$ catalyst (blue). The characteristic peaks of hcp-Co (green lines), fcc-Co (black lines) and $\mathrm{Al}_{2} \mathrm{O}_{3}$ (asterisks) are also marked.

The presence of ligands on the surface of the catalytically active phase could be responsible for the reduction of the catalytic activity by blocking part of the catalyst active sites. ${ }^{[18]}$ Several efforts in order to remove the excess of ligands have been performed. The best results were obtained by a heat treatment at $270^{\circ} \mathrm{C}$ for 20 minutes under a flow of $\mathrm{Ar} / \mathrm{H}_{2}$ and under dynamic vacuum. This treatment decreases the amount of residual ligand to $3 \%$ instead of $8.4 \%$ for the as-made catalyst as determined by TGA, while conserving the hcp structure and the anisotropic shape (Figure S9 in SI for TEM and XRD). The thermally treated catalyst was also tested under similar conditions (Figure 4). The performances of all catalysts in terms of activity, selectivity and stability at 200 hours TOS are presented in Table 1.

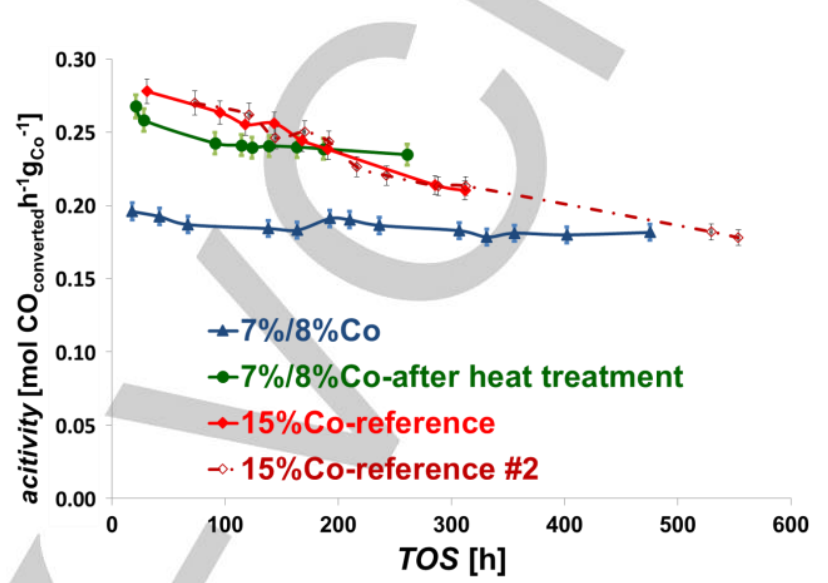

Figure 4. Catalytic activities versus TOS of the: $7 \% / 8 \%$ Co catalyst (in blue), and the 7\%/8\%Co-catalyst after heat treatment (in green) and the $15 \% \mathrm{Co}-\mathrm{SiO}_{2}$ $\mathrm{Al}_{2} \mathrm{O}_{3}$ reference catalyst (in red) The catalytic evaluation marked \#2 corresponds to a longer evaluation of the same reference catalyst $15 \% \mathrm{Co}-\mathrm{SiO}_{2}-\mathrm{Al}_{2} \mathrm{O}_{3}$ over a longer period, in order to demonstrate the reproducibility of the results.

Interestingly, the thermally treated $7 \% \mathrm{Co} / 8 \% \mathrm{Co} / \mathrm{SiO}_{2}-\mathrm{Al}_{2} \mathrm{O}_{3}$ catalyst shows the best activity, that exceeds the one of reference catalyst after $200 \mathrm{~h}$ TOS, combined to an excellent stability, which is one of the main concerns in industrial processes. While the available data do not allow drawing safe conclusions concerning structure-performance relationships, we propose that the high stability of the modified catalysts is probably connected to the absence of sintering as evidenced by the TEM examination of the spent catalyst. No large Co particles, which could have been formed by migration of small particles to the surface of the catalyst grains, ${ }^{[19]}$ were observed (Fig.S8 in SI), whereas a Co extraction and sintering effect is clearly observed for the reference catalyst (Figure S10, SI).The CoO content of the spent catalyst seems to be reduced compared to the fresh one (Fig.S8), which points towards an increased stability towards oxidation. We do not detect carbide formation, which is also a classical deactivation pathway of cobalt catalysts in FTS. The presence of large quantities of hcpCo less prone to form $\mathrm{Co}_{2} \mathrm{C}$ than $f_{C C}-\mathrm{Co}^{[20]}$ could be an explanation. The selectivity to undesired light products and in particular to methane can be ranked as follows: thermally treated $7 \% \mathrm{Co} / 8 \% \mathrm{Co} / \mathrm{SiO}_{2}-\mathrm{Al}_{2} \mathrm{O}_{3}>7 \% \mathrm{Co} / 8 \% \mathrm{Co} / \mathrm{SiO}_{2}-\mathrm{Al}_{2} \mathrm{O}_{3}>$ reference catalyst $15 \% \mathrm{Co} / \mathrm{SiO}_{2}-\mathrm{Al}_{2} \mathrm{O}_{3}$. The selectivity to longer chains is decreased for the thermally treated sample. This tendency is not yet understood and further studies would be needed to rationalize it, however, it is possible that the presence of remaining ligands on the surface of the cobalt particles for the non-treated sample neutralizes unselective sites. It is worth mentioning that higher methane selectivity have already been observed, but not rationalized, for $h c p$-Co catalysts. ${ }^{[8 e, 21]}$ 
Finally, it has to be noted that the anisotropically grown cobalt domains have not a constant diameter throughout their total length, but their diameter diminishes upon growing. This means that they do not adopt a perfect NR shape, therefore the exposed facets are not the (11-20) facets adopted by the regular NRs. ${ }^{[10]}$ Furthermore, the anisotropic domains grow from Co seed-particle facets (the ones of the Co particles of the conventional catalyst) that are not homogeneous in size so different pods of the multipods are most likely enclosed by different facets. Therefore, any correlation of the catalytic performances of the modified catalysts to specific facets is not possible.

\section{Conclusions}

The present work is an example of the possibilities offered by colloidal chemistry methods for the synthesis of nano-objects in the domain of heterogeneous catalysis. We have shown that cobalt nano-objects of $h c p$ crystal structure and anisotropic shape can be grown on the surface of Co particles of a conventional catalyst, from a solution containing a molecular Co precursor and organic stabilizers. While the initial activity of the modified catalyst is inferior to the one of the conventional catalystits stability is far superior. As the catalytic run progresses, the activity of the modified catalyst at least attains the one of the conventional catalyst. The urchin shape of the hcp-Co phase is not retained under the conditions employed for the FTS, however, its metallic state, and more precisely the $h c p$ structure, remains intact. Furthermore, while the NR shape is not maintained in the spent catalyst, no sintering has been observed. The fact that the catalytically active phase remains well dispersed throughout the reaction, as well as the conservation of its metallic character are probably the reasons for the increased catalyst stability. Elimination of a great part of the native organic ligands increases catalyst activity, without compromising its stability. These results demonstrate that colloidal methods for the synthesis of metal nano-objects can be exploited, allowing adding and/or modifying specific structural characteristics of classical heterogeneous catalysts. Since the catalytic phase microstructure might determine catalyst reactivity, such modifications may allow improvement of several other catalytic systems.

Table 1. Catalyst performances at 200 hours TOS.

\begin{tabular}{|c|c|c|c|c|c|c|}
\hline \multirow{2}{*}{ Catalyst } & \multirow{2}{*}{$\begin{array}{c}\text { Activity } \\
(\mathrm{mol} \text { CO converted/h/gco })\end{array}$} & \multicolumn{4}{|c|}{ Selectivity (\%) ${ }^{[a]}$} & \multirow{2}{*}{ Stability ${ }^{[b]}$} \\
\hline & & $\mathrm{CO}_{2}$ & $\mathrm{CH}_{4}$ & $\mathrm{C}_{2-4}$ & $\mathrm{C}_{5+}$ & \\
\hline $15 \%$ Co-Ref & 0.24 & 0.6 & 9 & 8 & 82 & 1.00 \\
\hline $7 \% / 8 \% \mathrm{Co}$ & 0.19 & 0.6 & 11 & 10 & 79 & 7.68 \\
\hline $7 \% / 8 \%$ Co-after heat treatment & 0.24 & 0.9 & 14 & 13 & 68 & 6.15 \\
\hline
\end{tabular}

${ }^{[a]}$ Expressed in weight percentage over the total product mass \% w/w. ${ }^{[b]}$ Expressed as the ratio of activity vs. time slope at $200 \mathrm{~h}$ between reference and said catalyst.

\section{Experimental Section}

\section{General methods}

$\mathrm{Co}\left(\mathrm{NO}_{3}\right)_{2}, 6 \mathrm{H}_{2} \mathrm{O}$ was purchased from Alfa Aesar (purity 98\%), silicaalumina from Sasol Gmbh. Hexadecylamine (HDA) was purchased from Aldrich (purity 98\%), lauric acid (LA) from Acros (purity 99\%), and the Co precursor $\left[\mathrm{Co}\left\{\mathrm{N}\left(\mathrm{SiMe}_{3}\right)_{2}\right\}_{2}(\mathrm{thf})\right]^{[22]}$ from NanoMeps. These products were introduced in a glove-box and used without any further purification. Toluene was purchased from Fischer Chemical (purity 99\%), distilled and degassed by argon bubbling. It was then introduced in a glove box and kept under molecular sieves.

\section{Catalyst preparation}

\section{$\mathrm{Co} / \mathrm{Al}_{2} \mathrm{O}_{3}-\mathrm{SiO}_{2}$ catalyst}

The conventional cobalt catalyst was prepared by incipient wetness impregnation of a $\mathrm{Co}\left(\mathrm{NO}_{3}\right)_{2}, 6 \mathrm{H}_{2} \mathrm{O}$ aqueous solution on a powder silicaalumina $\mathrm{Al}_{2} \mathrm{O}_{3}-\mathrm{SiO}_{2}\left(\mathrm{Al}_{2} \mathrm{O}_{3}: 95 \%, \mathrm{SiO}_{2}: 5 \%-\mathrm{S}_{\mathrm{BET}}=171 \mathrm{~m}^{2} \cdot \mathrm{g}^{-1}\right.$ - pore volume $=0.52 \mathrm{~cm}^{3} \cdot \mathrm{g}^{-1}-$ mean pore diameter $=9.2 \mathrm{~nm}$, average particle size $=50 \mu \mathrm{m})$. After the impregnation step, the solid was dried under air flow at $85^{\circ} \mathrm{C}$ during $5 \mathrm{~h}$ and then calcined at $400^{\circ} \mathrm{C}$ during $4 \mathrm{~h}$. For loadings of $7 \%$ cobalt, only one step was necessary, whereas in the case of a catalyst containing $15 \%$ cobalt, the impregnation drying and calcination steps where carried out twice. The final oxide obtained was then reduced under pure hydrogen at $400^{\circ} \mathrm{C}$ during $16 \mathrm{~h}$ and transferred in a solution of heptane without exposition to air. The catalyst obtained after activation will be called hereafter $\mathrm{XCo} / \mathrm{Al}_{2} \mathrm{O}_{3}-\mathrm{SiO}_{2}, \mathrm{X}$ being the amount of cobalt in the solid.

\section{$7 \% \mathrm{Co} / 8 \% \mathrm{Co} / \mathrm{SiO}_{2}-\mathrm{Al}_{2} \mathrm{O}_{3}$ catalyst}

For the growth of $h c p$ Co on $\mathrm{Co} / \mathrm{Al}_{2} \mathrm{O}_{3}-\mathrm{SiO}_{2}$ catalysts all experiments were performed under inert conditions, in the interior of a glove box or by using standard Schlenk techniques due to the air sensitivity of the metal precursors, as well as of the Co-particles. Typically, in a Fischer Porter bottle, a solution of [Co(N(SiMes)2)(thf)] $(646.2 \mathrm{mg}, 1.4 \mathrm{mmol})$ in $2 \mathrm{~mL}$ of toluene was added at room temperature to a solution of a mixture of LA (870.0 mg, $4.2 \mathrm{mmol}$ ) and HDA (700.2 mg, $2.8 \mathrm{mmol})$ in toluene $(100 \mathrm{~mL})$. Then $1.2 \mathrm{~g}$ of the $8 \% \mathrm{Co} / \mathrm{SiO}_{2}-\mathrm{Al}_{2} \mathrm{O}_{3}$ catalyst were added to the violet solution and let under stirring at room temperature for 10 minutes. The resulting mixture was heated at $110^{\circ} \mathrm{C}$ during 24 hours under 3 bars of hydrogen. At the end of the reaction, the mixture was transferred into the glove box. The black precipitate was separated from the supernatant colorless transparent solution, and washed three times with $200 \mathrm{~mL}$ of 
toluene, and finally with $50 \mathrm{~mL}$ of pentane and dried $(1,870 \mathrm{gr})$. For catalytic performance evaluation, the as-prepared catalyst was stored in $\mathrm{n}-\mathrm{C}_{22}$ wax in order to protect it from reoxidation before testing.

The thermal treatment performed in order to reduce the organic content in the catalyst was realized under controlled atmosphere in a tubular oven. The sample was heated under a flow of $\mathrm{Ar} / \mathrm{H}_{2}(93 \% / 7 \%)$ continuously pumped under vacuum to $250^{\circ} \mathrm{C}$ at a $20^{\circ} \mathrm{C} / \mathrm{min}$ rate, then to $270^{\circ} \mathrm{C}$ at a $2^{\circ} \mathrm{C} / \mathrm{min}$, followed by a step of 20 minutes at $270^{\circ} \mathrm{C}$, then the sample was left to cool down under gas flow, and transferred back into the glove box.

\section{Catalyst characterization}

Transmission Electron Microscopy (TEM) observations were carried out on a JEOL JEM 1400 and a JEOL JEM 2100F. The $70 \mathrm{~nm}$ ultra-microtomy slices were obtained by embedding the sample in an epoxy resin prior to the cutting $70 \mathrm{~nm}$ slices with a UCT ultramicrotome (Leica Microsystems). The slices were deposited on TEM grids to allow the observations. FEGSEM (Field Emission Gun-Scanning Electron Microscopy) observations were carried out on a JEOL 7800F. XRD analyses were performed on a Panalytical Empyrean (Co Ka $=1.789010 \AA$ ) diffractometer (Highscore software) and on a PANalytical X'Pert Pro $\left(\mathrm{Cu} \mathrm{K} \mathrm{K}_{a 1}=1.5406 \AA\right)$ diffractometer (EVA software). ICDD database was used for the data interpretation. The ICP measurements were carried out at the analytical service of the LCC (Laboratoire de Chimie de Coordination) after digestion in nitric acid. The TGA analyses were performed on a TGA/DSC 1 Star System from Metler Toledo. The sample was heated at a $10^{\circ} \mathrm{C} /$ minute rate between $25^{\circ} \mathrm{C}$ and $500^{\circ} \mathrm{C}$ followed by a two hours step at $500^{\circ} \mathrm{C}$.

\section{Catalytic runs and product analysis}

The Fischer-Tropsch reaction was carried out in a CSTR at $220^{\circ} \mathrm{C}, 20$ bars, $\mathrm{H}_{2} / \mathrm{CO}=2$. A mass of 2 to $3 \mathrm{~g}$ of catalyst was loaded in the reactor prefilled with n-C22 solvent in order to prevent re-oxidation of the catalyst. The conversion was maintained at $45 \%$ for all the catalysts by adjusting the inlet syngas flow in order to compare the selectivity at iso-conversion for all the solids.

The gas phase was analyzed by on-line gas chromatography. Analysis of permanent gases was performed using a Molecular Sieve column (5A) and a thermal conductivity detector. Hydrocarbons were separated in a PONA column and analyzed by a flame ionization detector. An external calibration of the chromatograph performed once a day. This gave access to CO conversion, activity (CO conversion x CO molar flow/Co mass), and selectivity in: $\mathrm{CH}_{4}, \mathrm{CO}_{2}$, light compounds (C2-C4), heavy compounds with more than $5 \mathrm{C}$ atoms (C5+). A standard deviation for $\mathrm{GC}$ analysis of $3 \%$ relative is considered. The total mass balance was calculated at each product collecting time by weighing liquid products (water and waxes) and measuring gaseous components, and kept between $97 \%$ and $103 \%$

\section{Acknowledgements}

J. Harmel thanks the Université de Toulouse (Nysfit project $\mathrm{N}^{\circ}$. 6013 ) and the Région Midi Pyrénées (Nysfit project $\mathrm{N}^{\circ}$. 13050269) for financial support. This study has been partially supported through the grant NEXT N ${ }^{\circ}$. ANR-10-LABX-0037 in the framework of the "Programme des Investissements d'Avenir".

Keywords: colloids•nanocatalysis • supported catalysis • Fischer-Tropsch reaction $\bullet$ nanowires
[1] a) T. S.Ahmadi, Z. L. Zhong, T. C. Green, A. Hengelein, M. A. El-Sayed, Science 1996, 272, 1924-1926; b) Y. Li, G. A. Somorjai, Nano Lett. 2010, 10, 2289-2295; c) R. Schlögl; Angew. Chem., Int. Ed. 2015, 54, 3465 3520; d) F. Zaera, Chem. Soc. Rev. 2013, 42, 2746-2762; d) F. Zaera, ChemSusChem 2013, 6, 1797-1820.

[2] a) Y. Yin, A. P. Alivisatos, Nature, 2005, 437, 664-670; Y. Xia, Y. Xiong, B. Lim, S. E. Skrabalak, Angew. Chem., Int. Ed. 2009, 48, 60-103.

[3] A. T. Bell Science 2003, 299, 1688-1691.

[4] a) R. B. Anderson, The Fischer-Tropsch Synthesis, Academic Press, NewYork, 1984; b) H. Jahangiri, J. Bennett, P. Mahjoubi, K. Wilson and S. Gu, Catal.Sci.\& Technol. 2014, 4, 2210-2229; c) A. Y. Khodakov, W. Chu and P. Fongarland, Chem. Rev. 2007, 107, 1692-1744; d) G. P. Van Der Laan and A. A. C. M. Beenackers, Catal. Rev. 1999, 41, 255-318.

[5] a) M. E. Dry, Catal. Today 2002, 71, 227-241; b) A. P. Steynberg, R. L. Espinoza, B. Jager and A. C. Vosloo, Appl. Catal. A: General 1999, 186, 41-54; c) G. L. Bezemer, J. H. Bitter, H. P. C. E. Kuipers,H. Oosterbeek J. E. Holewijn, X. Xu, F. Kapteijn, A. J. van Dillen, K. P. de Jong, J. Am. Chem. Soc., 2006, 128, 39563964.

[6] B. Jager and R. Espinoza, Catal. Today, 1995, 23, 17-28.

[7] G. van Helden, I. M. Ciobica and R. L. J. Coetzer, Catal. Today, 2016, 261, 48-59.

[8] a) M. Sadeqzadeh, H. Karaca, O.V. Safonova, P. Fongarland, S. Chambrey, P. Roussel, A. Griboval-Constant, M. Lacroix, D. CurullaFerré, F. Luck, and A.Y. Khodakov, Catal. Today 2011, 164, 62-67 b) M K. Gnanamani, G. Jacobs, W. D. Shafer and B. H. Davis, Catal. Today 2013, 215, 13-17; c) O. Ducreux, B. Rebours, J. Lynch, M. Roy-Auberger and D. Bazin, Oil \& Gas Sci. Technol. - Rev. IFP, 2009, 64, 49-62; d) H. Karaca, O. V. Safonova, S. Chambrey, P. Fongarland, P. Roussel, A. Griboval-Constant, M. Lacroix and A. Y. Khodakov, J. Catal. 2011, 277, 14-26; e) G. Kwak, D.-E. Kim, Y. T. Kim, H.-G. Park, S. C. Kang, K.-S. Ha, K.-W. Jun, Y.-J. Lee, Catal. Sci. \& Technol. 2016, 6, 4594-4600.

[9] J.-X. Liu, H.-Y. Su, D.-P. Sun, B.-Y. Zhang and W.-X. Li, J. Am. Chem. Soc. 2013, 135, 16284-16287

[10] a) F. Wetz, K. Soulantica, M. Respaud, A. Falqui, B. Chaudret Mat. Sci. Eng. C. 2007, 27, 1162-1166 ; b) B. Cormary, T. Li, N. Liakakos, L. Peres, P.F. Fazzini, T. Blon, M. Respaud, A. J. Kropf, B. Chaudret, J. T Miller, E. A. Mader, K. Soulantica J. Am. Chem. Soc. 2016, 138, 8422-8431. [11] a) E. Rytter and A. Holmen, Catalysts, 2015, 5, 478-499; b) N. E. Tsakoumis, M. Rønning, Ø. Borg, E. Rytter and A. Holmen, Catal. Today 2010, 154, 162-182; c) A. M. Saib, D. J. Moodley, I. M. Ciobîcă, M. M. Hauman, B. H. Sigwebela, C. J. Weststrate, J. W. Niemantsverdriet and J. van de Loosdrecht, Catal. Today 2010, 154, 271-282; d) S. Karimi, A. Tavasoli, Y. Mortazavi, A. Karimi, Chem. Eng. Res. Des. 2015, 104, 713722.

[12] a) A. Y. Khodakov, Catal. Today, 2009, 144, 251-257; b) T. Fu and Z. Li, Chem. Eng. Sci. 2015, 135, 3-20; c) G. Prieto, M. I. S. De Mello, P. Concepción, R. Murciano, S. B. C. Pergher and A. N. Martínez, ACS Catalysis 2015, 5, 3323-3335; d) G. Jacobs, W. Ma and B. Davis, Catalysts 2014, 4, 49.

[13] J. Harmel, A. Soulantika, P. Serp, B. Chaudret, A. Berliet, A. Fecant and M. Maury WO 2016/193295.

[14] F. Dumestre, B. Chaudret, C. Amiens, M. Respaud, P. Fejes, P. Renaud and P. Zurcher, Angew. Chem., Int. Ed. 2003, 42, 5213-5216.

[15] Y. Xia, K. D. Gilroy, H.-C. Peng, and X. Xia, Angew. Chem. Int. Ed. 2002 $56,60-95$.

[16] a) N. Liakakos, T.Blon, C. Achkar, V. Vilar, B. Cormary ,R. P. Tan, O Benamara, G. Chaboussant, F. Ott, B. Warot-Fonrose, E. Snoeck, B. Chaudret, K. Soulantica and M. Respaud, NanoLett. 2014, 14, 3481 3486. b) N. Liakakos, C. Achkar, B. Cormary, J. Harmel, B. WarotFonrose, E. Snoeck, B. Chaudret, M. Respaud, K. Soulantica and T. Blon, ACS Nano 2015, 9, 9665-9677.

[17] N. Liakakos, B.Cormary, X. Li, P. Lecante, M. Respaud, L. Maron, A. Falqui, A. Genovese, L. Vendier, S. Koïnis, B. Chaudret, K. Soulantica, J. Am. Chem. Soc. 2012, 134, 17922. 


\section{FULL PAPER}

[18] S. Campisi, M. Schiavoni, C. E. Chan-Thaw and A. Villa, Catalysts 2016, 6, 185.

[19] P. Munnik, P. E. de Jongh, K. P. de Jong, J. Am. Chem. Soc. 2014, 136, 7333-7340.

[20] K. H. Cats, B. M. Weckhuysen, ChemCatChem 2016, 8, 1531-1542.

[21] M. Claeys, M. E. Dry, E. van Steen, E. du Plessis, P.J. van Berge, A.M. Saib, D.J. Moodley, J. Catal. 2014, 318, 193-202. [22] B. Cormary, F. Dumestre, N. Liakakos, K. Soulantica and B. Chaudret, Dalton Trans. 2013, 42, 12546-12553.

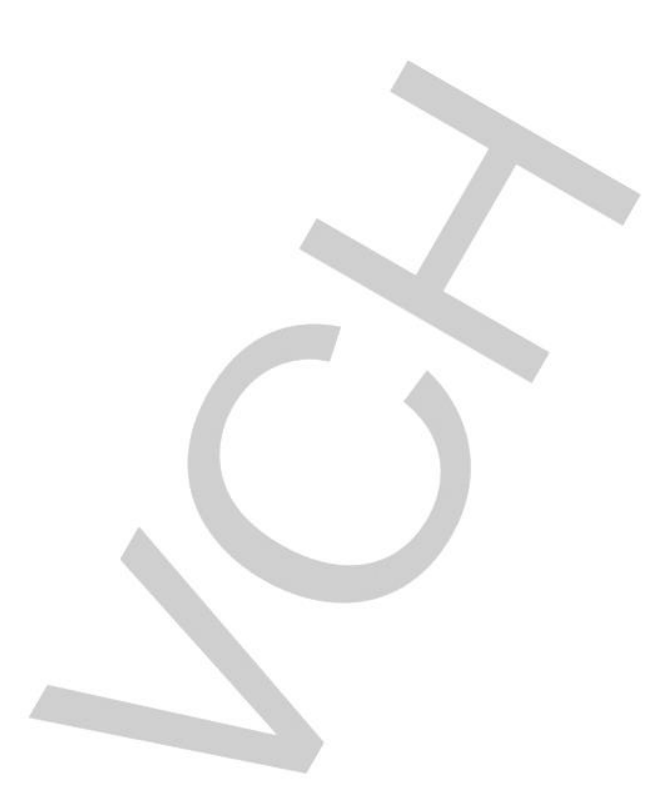


WILEY-VCH

\section{FULL PAPER}

Cobalt nanowires have been grown on the cobalt particles of a conventional Fischer-Tropsch catalyst by a seededgrowth strategy, employed in the wet chemistry synthesis of nanoparticles. This modification stabilizes the catalyst

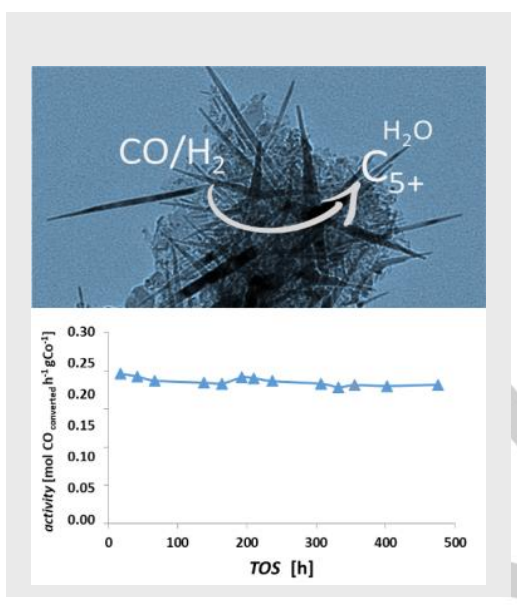

J. Harmel, A. Berliet, K. Dembélé, C. Marcelot, A.-S. Gay, O. Ersen, S. Maury, A. Fécant, B. Chaudret, P. Serp, ${ }^{*} K$. Soulantica*

\section{Page No. - Page No.}

A seed-mediated approach for the preparation of modified heterogeneous catalysts

Layout 2:

\section{FULL PAPER}
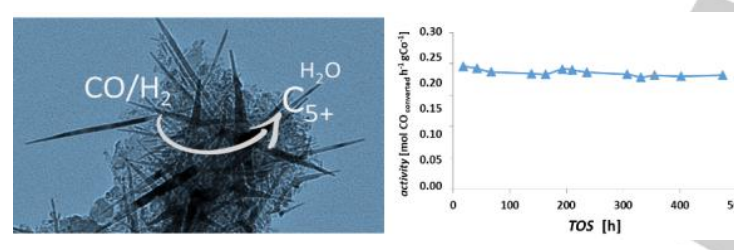

have been grown on the cobalt particles of a conventional Fischer-Tropsch catal by a seeded-growth strategy, employed in the wet chemistry synthesis of nanoparticles. This modification stabilizes the catalyst.
J. Harmel, A. Berliet, K. Dembélé, C. Marcelot, A.-S. Gay, O. Ersen, S. Maury, A. Fécant, B. Chaudret, P. Serp, ${ }^{*} K$. Soulantica*

Page No. - Page No.

A seed-mediated approach for the preparation of modified heterogeneous catalysts 
WILEY-VCH

FULL PAPER 